ZBYSZKO MELOSIK

Uniwersytet im. Adama Mickiewicza

w Poznaniu

\title{
PIEKA NOŻNA, STYL ŻYCIA I PROCESY REPRODUKCJI KULTUROWEJ W STANACH ZJEDNOCZONYCH
}

ABSTRACT. Melosik Zbyszko, Piłka nożna, styl życia i procesy reprodukcji kulturowej w Stanach Zjednoczonych [Soccer, Lifestyle and the Process of Cultural Reproduction in the United States of America]. Studia Edukacyjne nr 42, 2016, Poznań 2016, pp. 119-130. Adam Mickiewicz University Press. ISSN 1233-6688. DOI: $10.14746 /$ se.2016.42.7

In his article the author considers the paradox of soccer appropriation in the United States. It is rejected by majority of Americans at the professional level as they prefer football, basketball and baseball. However, at the recreational level soccer is used by middle class and upper middle class as a form of their status confirmation and for cultural reproduction. The symbol of such an approach is analysed - the "soccer mom" as a person who considers soccer as a very valuable exercise experience for her daughters and sons.

Key words: soccer, lifestyle, middle class, recreation, cultural reproduction, soccer mom

W moim tekście poświęconym recepcji piłki nożnej przez Stany Zjednoczone przedstawiłem dynamikę napięcia między tą dyscypliną sportową a ideologią amerykańskiego izolacjonizmu1. Piłka nożna jest wykluczana z "głównego nurtu" sportu amerykańskiego; nie ma żadnych szans na zdobycie spektakularnej popularności. Piłkarze nie są popularnymi bohaterami ani postaciami medialnymi. A jednak, bogactwo społeczno-kulturowe Ameryki zdaje się nieskończone i pełne mnożących się paradoksów. I tak, „oficjalnej" ideologicznej krytyce piłki nożnej, przeciwstawianej amerykańskie$\mathrm{mu}$ footballowi, towarzyszy jej rosnąca rola jako instrumentu reprodukcji

1 Patrz: Studia Edukacyjne, 2016, 41. 
kulturowej i stratyfikacji społecznej. Poniżej przedstawione zostaną najbardziej istotne konteksty tego problemu.

$\mathrm{O}$ ile na poziomie profesjonalnym piłka nożna rozwija się $\mathrm{w}$ Stanach Zjednoczonych bardzo powoli i więcej jest tutaj upadków niż wzlotów, to na poziomie rekreacyjnym staje się sportem numer jeden - szczególnie wśród młodzieży szkolnej (w tym dziewcząt) i szczególnie wśród klas średnich oraz wyższych. Można wyjść od tezy Hilary Levey Friedman:

Sport jest dosyć ważny w kulturze amerykańskiej wyższej klasy średniej. „Dramatyzuje on i uprawomocnia pewne wartości, które cechują środowiska pracy zawodowej wyższej klasy średniej: to znaczy konkurencyjność, męską przyjaźń i męskość"2.

Logicznie, w takie wartości wpisują się tradycyjne sporty amerykańskie, a przede wszystkim koszykówka i football amerykański. Jednakże, w przypadku swoich dzieci Amerykanie z wyższych klas społecznych często nie akceptują tych sportów jako wartych uprawiania.

Biali rodzice postrzegają również piłkę nożną jako antidotum na koszykówkę - jako sport zdominowany przez czarnych i ich cielesność, którą uosabiają jako zagrażającą ich białej supremacji ${ }^{3}$. Piłka nożna jest przedmiejska, biała, bardziej intelektualna, a koszykówka - śródmiejska, czarna i fizyczna4. Piłka nożna dostarcza białym poczucia moralnej i kulturowej nadrzędności nad czarnymi. Uważa się, że stanowi ona formę zdrowej rekreacji, a nie "grę dla pieniędzy". Jest to sport rodzinny ${ }^{5}$. Akceptacja piłki nożnej przez klasy średnie i wyższe ma więc na celu zdystansowanie się wobec sportów, które uważane są za typowe dla klasy pracującej lub dla czarnego getta: footballu amerykańskiego i koszykówkíi . Piłka nożna uważana jest za „zdrową alternatywę" dla postrzeganej często za patologiczną i agresywną męskość kultywowaną $\mathrm{w}$ ramach footballu amerykańskiego. Uważa się, że rozwija ona umiejętność współpracy $\mathrm{w}$ zespole oraz orientację na pozbawione agresji współzawodnictwo i osiągnięcia, a cechy te mogą być bardzo

${ }^{2}$ H.L. Friedman, Playing to Win. Raising Children in a Competitive Culture, Berkeley 2013, s. $123-124$.

${ }^{3} \mathrm{Na}$ ten temat por. Z. Melosik, Kryzys męskości w kulturze wspótczesnej, Kraków 2006; szczególnie fragment zatytułowany: „Czarne męskie ciało i kryzys białej męskości”.

4 D.L. Andrews i in., Soccer, Race, and Suburban Space, [w:] Sporting Dystopias: The Making and Meaning of Urban Sport Cultures, red. R.C. Wilcox, D.L. Andrews, R. Pitter, R.L. Irvin, Albany 2003 , s. 211.

5 Tamże, s. 213.

${ }^{6}$ M. Hase, Race in Soccer as a Global Sport, [w:] Sports Matters. Race, Recreation and Culture, red. J. Bloom, M.N. Willard, New York 2002, s. 313. 
przydatne $\mathrm{w}$ innych sferach życia. Ponadto, pomaga utrzymywać dzieci "z dala od ulicy"7.

Tradycja zainteresowania yuppies („młodych miejskich profesjonalistów") rekreacyjną wersją piłki nożnej sięga ostatnich dwóch dekad dwudziestego wieku. Akceptowali oni udział swoich dzieci w meczach, postrzeganych jako niekonfrontacyjne, pozbawione przemocy, często koedukacyjne (na zasadzie „nieważne kto wygra, ważne aby miło spędzić czas”)

O zjawisku tym Andrei S. Markovits i Lars Rensmann piszą następująco:

Nagle, piłka nożna w Ameryce, pozwoliła dzieciom z wyższej klasy średniej, posiadającym kosmopolitycznych rodziców - którzy piją tylko najlepsze francuskie wina, podróżują często do Europy, siadają za kierownicą Volvo lub Saaba i uważają (...) cztery wielkie sporty [koszykówka, football, baseball i hokej na lodzie] za niekulturalne - znaleźć (...) poprawny sport zespołowy (...). Piłka nożna stała się w Ameryce anty-footballem; była [ona] preferowana przez eurofilską, związaną z wyższą klasą średnią społeczność, [która] postrzegała football (i inne pozostałe sporty z wielkiej czwórki) jako brutalne, przesycone ideologią machismu i całkowicie zorientowane na zwycięstwo9.

Piłka nożna stanowi więc - w oczach rodziców z klasy średniej urodzonych po 1960 roku - antidotum na hipermaskulinizowany i seksistowski football amerykański ${ }^{10}$. Postrzegana jest niemal jako „aerobic”, sport dla zdrowia i wpisujący się w estetykę klasy średniej. Wręcz nie jest traktowana jako sport kontaktowy ${ }^{11}$.

Piłka nożna stała się zatem w Stanach Zjednoczonych częścią „społecznie różnicującego i wysoko wystylizowanego stylu życia, poprzez który jednostki pragną stać się członkami cenionej przez nie podmiejskiej klasy średniej”12. Może być postrzegana w tym kraju jako „biały, przynależny do klasy średniej sport, znajdujący się w opozycji do demografii tej dyscypliny na całym świecie"13. Dla bogatych Amerykanów stanowi ona wyraz ich kapitału kulturowego i ekonomicznego, wraz z przynależnością do ekskluzywnych stowarzyszeń, zakupami w drogich domach towarowych (i dodam

7 D.L. Andrews, Contextualizing Suburban Soccer: Consumer Culture, Lifestyle Differentiation and Suburban America, [w:] Football Culture: Local Contests, Global Visions, red. G.P.T. Finn, R. Giulianotti, London 2000, s. 48.

8 A.S. Markovits, S.L. Hellerman, Offside: Soccer and American Exceptionalism, Princeton 2001, s. 171.

9 A.S. Markovits, L. Rensmann, Gaming the World. How Sports are Reshaping Global Politics and Culture, Woodstock 2010, s. 185.

${ }^{10}$ D.L. Andrews i in., Soccer, Race, and Suburban Space, s. 209.

11 Tamże, s. 211.

12 D.L. Andrews, Contextualizing Suburban, s. 32.

${ }^{13}$ Por. tamże, s. 38. 
- posyłaniem dzieci do dobrych szkół średnich) ${ }^{14}$. Dla majętnych rodziców piłka nożna jest częścią „edukacyjnego programu”, tworzenia właściwego wizerunku i rozwijania "kapitału kulturowego” swoich dzieci. Stała się symbolem statusu15. Jak ironicznie pisze Franklin Foer, „Yuppies lubią piłkę nożną jak wyśmienity kawałek importowanego koziego sera"16. Rodzice „myślą o piłce nożnej jako tej wzbogacającej dzieci aktywności, która może przeplatać się z lekcjami gry na fortepianie"17. Nie jest ona uważana za sport, ale za formę rekreacji rodzinnej.

Warto w tym miejscu przytoczyć uwagi Davida L. Andrewsa:

Podmiejska kultura piłki nożnej uwidacznia zakres, do którego coraz więcej prozaicznych aspektów wolnego czasu dzieci jest pochłonięta przez normalizujący konkurencyjny etos obowiązującego stylu życia: ta "generacja rodziców... rozpoczyna swoje działania wobec coraz mniejszych dzieci, zmuszając ich do coraz cięższej pracy, nie tylko w dziedzinie piłki nożnej, ale także muzyce, trudnych do dostania się przedszkolach, balecie, językach obcych"18.

Dzieci nie mogą już spędzać swojego wolnego czasu w sposób dowolny, lecz tworzy się dla nich

komercyjnie zorganizowane formy „rozszerzonej edukacji”, niekiedy mimo finansowych, logistycznych, a także emocjonalnych problemów z tym związanych - zarówno dzieci, jak i rodziców.

Celem jest tutaj "widoczne kształtowanie zdrowych, zdolnych do współpracy, zorientowanych na realizację celu, konkurencyjnych dzieci" 19.

Warto przywołać w tym miejscu pojęcie soccer mom („piłkarskiej mamusi") - pojęcie odnoszące się do amerykańskiej matki z klasy średniej, żyjącej na przedmieściach, która spędza bardzo dużą ilość czasu na organizowaniu swoim dzieciom uczestnictwa $\mathrm{w}$ pozaszkolnych zajęciach dodatkowych, w tym także sportowych. Nieustannie zajęta i przepracowana, spędza każdego dnia wiele godzin w samochodzie, poświęcając się dla dzieci - odwożąc je na owe zajęcia i czekając na ich zakończenie. "Soccer mom” ma swoje negatywne konotacje. Otóż, uważa się, że zmusza ona swoje dzieci do podejmowania coraz to nowych dodatkowych form aktywności, że jest „przerodzicowana" i nie pozwala dzieciom cieszyć się dzieciństwem. Koncentruje

14 Tamże, s. 45-46.

15 G.R. Gems, G. Pfister, Understanding American Sports, Abingdon 2009, s. 152.

${ }^{16}$ F. Foer, How Football Explains the World, London 2004, s. 238-239.

17 Por. dyskusję internetową na temat „Soccer mom”: why soccer?; 2014, adres internetowy: http://english.stackexchange.com/questions/180899/soccer-mom-why-soccer

${ }_{18}$ D.L. Andrews, Contextualizing Suburban.

${ }^{19}$ Por. tamże, s. 48. 
bowiem swoją uwagę na udziale dzieci w zorganizowanych formach zajęć, które mają rozwijać ich - niekiedy iluzoryczne - talenty, kosztem rozwoju wewnętrznego. Nie pozwala im na ekspresję samych siebie i zajmowanie się tym, co same uważają za ważne, ale jest też optymistyczna i otwarta na nowe idee ${ }^{20}$.

Szczególnie prezentuje się zaciekawienie piłką nożną przez amerykańskie dziewczęta. W przeszłości zainteresowania kobiet z wyższych klas społecznych były zorientowane na sztuki piękne. Obecnie wiele z nich trenuje różne dyscypliny sportowe, a piłka nożna jest jedną z najpopularniejszych ${ }^{21}$. W społeczeństwie amerykańskim kultywuje się dwa typy kobiecości. Jak pisze Hilary Levey Friedman, symbolem jednego z nich jest pełna wdzięku dziewczyna, która uprawia taniec, a na przeciwnym biegunie znajduje się coraz częściej preferowana przez klasy wyższe - asertywna i zdolna do agresji dziewczyna uprawiająca piłkę nożną 22 . Amerykańscy rodzice uważają, że piłka nożna kształci $\mathrm{w}$ dziewczętach tradycyjnie męskie cechy charakteru, które pomogą im w życiu: orientację na osiągnięcia, systematyczność, odporność, konkurencyjność i nawet pewną agresję. Taniec z kolei kształci emocjonalne zaangażowanie, urocze zachowanie i zainteresowanie wyglądem. Niezależnie od krytyki, jaka w Stanach Zjednoczonych odnosi się do „zniewieściałego" charakteru piłki nożnej, to jednak - zdaniem rodziców z wyższych klas społecznych - piłka nożna w dużym stopniu nawiązuje do ideału hegemonicznej męskości23. Uważają, że piłka nożna kształci w ich córkach (choć w sposób „miękki” w porównaniu z amerykańskim footballem) ową tradycyjnie męską orientację na zwycięstwo i wpisuje się w biografię zorientowaną na karierę zawodową ${ }^{24}$. Rodzice nie chcą, aby ich córki były girly girls - dziewczęcymi dziewczętami. W ich umysłach istnieje przekonanie, że piłka nożna dobrze przygotowuje ich do sukcesu w korporacjach $^{25}$.

Znaczący udział $\mathrm{w}$ amerykańskiej piłce nożnej dziewcząt oraz mniej agresywny - $\mathrm{w}$ porównaniu $\mathrm{z}$ amerykańskim footballem - styl gry $\mathrm{w}$ tej dyscyplinie wywołuje wiele ironicznych uwag. Warto przytoczyć jedną $\mathrm{z}$ nich, bowiem bardzo dobrze oddaje istotę problemu:

20 Por. dyskusję internetową na temat "Soccer mom": why soccer?; także interesującą dyskusję na temat tego problemu w: L. Swanson, Complicating the "Soccer Mom": The Cultural Politics of Forming Class-Based Identity, Distinction and Necessity, Research Quarterly for Excercise and Sport, 2009, 80, 2, s. 345-354.

${ }^{21}$ H.L. Friedman, Playing to Win, s. 123-124.

22 Tamże, s. 125.

23 Tamże, s. 129.

24 Tamże, s. 135.

25 Tamże. 
Piłka nożna jest dla dziewcząt, mogą w nią także grać zniewieściali chłopcy. Amerykański football jest dla silnych heroicznych mężczyzn. Jedynie bardzo silni mężczyźni przetrwają na boisku. Jeśli nie jesteś w stanie przetrwać wycisku, jaki ci dadzą [futboliści drużyny przeciwnej], to idź przespaceruj się na boisko piłkarskie, aby grać z dziewczętami i niewydarzonymi chłopaczkami26.

Inny krytyk pisze następująco:

Piłka nożna jest dla dzieci, które nie mają specjalnego talentu (...) Nie wymaga posiadania specjalnych cech fizycznych (...) i dziewczęta mogą w nią grać (...) Jeśli rodzice sądzą, że ich dziecko może stać się „kimś” w sporcie, wówczas uprawia ono koszykówkę, baseball lub football (...) W piłkę nożną można grać nawet wówczas, gdy nie jest się w tym dobrym (...) Każde z 11 dzieci na boisku od czasu do czasu kopie piłkę (...) To jest sport, który wybierają matki pragnące, aby ich dzieci dobrze o sobie myślały (...) Nie trzeba być wysokim lub szybkim ${ }^{27}$. Piłka nożna jest bardzo łatwym sportem i (...) łatwo pozwala na myślenie, że jest się dobrym na boisku, nawet jeśli jest się bardzo kiepskim²8.

Piłka nożna stała się także integralną częścią programu dydaktycznowychowawczego elitarnych amerykańskich szkół średnich oraz najlepszych placówek edukacji wyższej. Oferta sportowa jednej z najlepszych szkół średnich z internatem dla dzieci z wyższych klas „Phillips Andover” jest wprost zdumiewająca (włączając $w$ to np. także lacrosse, hokeja na trawie dla dziewcząt, czy piłkę wodną) - towarzyszy jej wspaniała infrastruktura. Na internetowej stronie szkoły eksponuje się sukcesy zawodników i drużyn, wśród nich również piłkarskiej, a w szczególności - kobiecej. Kobieca reprezentacja Phillips Andover stanowi jedną z najlepszych wśród drużyn szkolnych w Nowej Anglii, a w latach 2007, 2009 i 2015 zdobyła mistrzostwo tego stanu w lidze drużyn najbardziej elitarnych szkół z internatem. Z terminarzu gier wynika, iż żeńska reprezentacja szkoły spotyka się w jesienią 2016 roku $\mathrm{w}$ rozgrywkach $\mathrm{z}$ reprezentacjami wielu innych znakomitych szkół średnich z internatem, mających swoją długą i "szlachetną" historię: Choate, Middlesex, St. Paul's, Deerfield, czy Exeter lub Groton. Jak napisano na stronie internetowej szkoły, jej sukcesy piłkarskie były możliwe dzięki „,iężkiej pracy i pasji”. Istotą piłki nożnej w Phillips Andover jest „rozwijanie technicznych i taktycznych kompetencji młodych ludzi”, z naciskiem na "ducha sportowej walki, wchodzenie $\mathrm{w}$ rolę lidera, ale także odpowiedzialnego członka zespołu" (w Andover istnieje kilka drużyn piłkarskich - dla

${ }^{26}$ Por. dyskusję internetową na temat piłki nożnej w Stanach Zjednoczonych i amerykańskiego footballu: Soccer vs. Football: Field Size; adres interntowy: http://themedia dude.blogspot.de/2006/06/soccer-vs-football-field-size.html

${ }^{27}$ Por. dyskusję internetową na temat: "Soccer mom": why soccer?

28 Tamże. 
uczniów w różnym wieku, zarówno chłopców jak i dziewcząt). Jednocześnie eksponuje się fakt, iż niektórzy absolwenci Phillips Andover kontynuują swoją karierę piłkarską w najlepszych amerykańskich placówkach edukacji wyższej, takich jak Harvard University, MIT, Trinity College, czy Cornell University ${ }^{29}$.

Warto w tym miejscu przytoczyć uwagi Gary Hopkinsa. Twierdzi on, że ogromnym paradoksem amerykańskiej młodzieżowej piłki nożnej jest to, że "grające obecnie w klubach dzieci to nie głodne dzieci z getta, które walczą o przetrwanie na ulicy, gotowe do poświęcenia wszystkiego za szansę na sukces". Są to głównie - z uwagi na strukturę społeczną swoich rodzin dzieci, które z całą pewnością w przyszłości ukończą znakomitą placówkę edukacji wyższej i uzyskają dyplom z prawa, medycyny, marketingu, czy bankowości. Oczywiście, część z nich marzy obecnie o światowej karierze piłkarskiej, ale ich biografie już są ułożone. Ich wykształceni rodzice, zarabiający zwykle więcej niż 80 tysięcy dolarów na rok, nie marzą o karierze piłkarskiej swoich dzieci, lecz o znakomitym wykształceniu i karierze zawodowej. I z tych powodów, jak twierdzi Gary Hopkins, „Stany Zjednoczone nigdy nie zdobędą mistrzostwa świata w piłce nożnej”30. Gra w piłkę nożną stanowi w tym kraju jedną ze ścieżek do dobrego koledżu, a nie do profesjonalnej kariery piłkarskiej - zupełnie inaczej niż jest to w większości krajów świata ${ }^{31}$. Rodzice nigdy nie podejmą ryzyka, aby ich dzieci zorientować na karierę piłkarską, a zmiana w tym zakresie musiałaby być poprzedzona, jak ujmuje to ten sam autor, „zmianą mentalności średniej klasy w Ameryce na miarę kataklizmu"32.

Dowodzą tego również dane statystyczne. Otóż, organizacja zrzeszająca młodych piłkarzy i piłkarki „US Youth Soccer” ma obecnie ponad trzy miliony zarejestrowanych osób w wieku 5-19 lat, o średniej wieku 11,5 lat, z czego aż $48 \%$ stanowią kobiety. $85 \%$ z nich liczy poniżej 14 lat, a tylko 3\% 18-19 lat, kiedy to podejmowane są decyzje dotyczące zarówno rozpoczęcia studiów, jak i dalszej kariery piłkarskiej33.

29 Por. Phillipis Academy Andover, Girls Varsity Soccer, 2015 New England Champions; adres internetowy:

http://www.andover.edu/Athletics/Teams/GSOV/Pages/default.aspx; na temat amerykańskiego elitarnego szkolnictwa średniego por. A. Gromkowska-Melosik, Elitarne szkolnictwo średnie. Między reprodukcją społeczno-kulturowa a ruchliwością konkurencyjna, Poznań 2015.

30 Por. G. Hopkins, Star-Spangled Soccer. The Selling, Marketing and Management of Soccer in the USA, New York 2010, s. 226.

31 Tamże, s. 227.

32 Tamże.

${ }^{33}$ US Youth Soccer, baza danych dotyczących młodzieżowej piłki nożnej w Stanach Zjednoczonych; adres internetowy: http:/ / www.usyouthsoccer.org/media_kit/ataglance/ 
Nie ulega więc wątpliwości, że piłka nożna w amerykańskich elitarnych szkołach średnich umieszczana jest jako dodatkowy „kredencjał” w kontekście całej akademickiej kariery młodego człowieka. Również elitarne amerykańskie uniwersytety mają bardzo bogatą ofertę dla studentów, a Harvard University jest jednym $\mathrm{z}$ tego przykładów.

Co ciekawe, $\mathrm{w}$ ramach uniwersyteckich przepisy gry w piłkę nożną różnią się od obowiązujących w piłce europejskiej. Na przykład, trener może zmienić podczas meczu nieograniczoną liczbę graczy, a zmieniony gracz może na boisko powrócić. Mecz nie może zakończyć się remisem: po zakończeniu 90 minuty gra toczy się dalej, aż do momentu, kiedy jedna z drużyn uzyska zwycięskiego gola. Z kolei, zegar boiskowy zatrzymuje się przy każdej przerwie w grze, zaś czas liczy się od 45 minuty do zera.

Piłka nożna stanowi więc nie tylko płaszczyznę reprodukcji społecznokulturowej, ale także stratyfikacji społecznej. Mamy tu do czynienia z maksymalną wprost komercjalizacją tego sportu, a de facto i młodzieży. Mike Slatton twierdzi, że młodzieżowa piłka nożna w Stanach Zjednoczonych nie jest zorientowana na sukcesy sportowe ani na podwyższanie kwalifikacji młodych zawodników, lecz stanowi jedynie „wielki biznes”. Związany jest on z pobieraniem opłat za treningi i udziały w obozach, czy zakupem drogiego sprzętu. Amerykańskie zespoły młodzieżowe są organizowane $\mathrm{w}$ taki sposób, aby symulować wspaniałe kluby europejskie, jednakże - jak ironicznie pisze autor - jedyne podobieństwo, to wspaniałe stroje piłkarskie i buty oraz kolorowe piłki, jak również wyposażenie stadionu. Piłka nożna jest więc sprzedawana rodzicom jako gotowa "oferta w paczce", niekiedy bardzo droga. W Europie istotą piłki młodzieżowej jest wynajdywanie talentów po to, aby umożliwić im w przyszłości profesjonalną karierę. W Stanach Zjednoczonych nikomu na tym nie zależy. Zajęcia są doskonale zorganizowane, trwają zwykle cztery godziny w tygodniu, a ich ukoronowaniem jest sobotni mecz. Cel ich organizatorów, właścicieli klubów stanowi posiadanie jak największej liczby zespołów w różnych grupach wiekowych, co pozwala na multiplikowanie zysków. Nie interesują się poziomem rozgrywanych meczów.

W Stanach Zjednoczonych mamy tylko jedną piłkę nożną - rekreacyjną. Jej symbolem są bardzo efektowne stroje trenerów i dzieci, wspaniałe kompleksy sportowe i kolorowe światła (co ma sprawiać wrażenie, że jest to coś więcej niż tylko rekreacja); jednak smutną prawdą jest to, że jest to jedynie rozrywka. $W$ takim systemie twój syn nigdy nie stanie się zawodowym graczem² ${ }^{34}$.

${ }^{34}$ M. Slatton, Where does all the money go? (Youth Soccer Fees), 2.12.2012; portal internetowy: „Soccer Mom. The Manual. Explanations, clarifications and opinions on Youth Soccer in America"; https:// soccermommanual.com/where-does-all-the-money-go-youth-soccer-fees/ 
Działalność skomercjalizowanych klubów można przedstawić na przykładzie klubu "Solar Chelsea”, którego nazwa nawiązuje do jednego z najbardziej renomowanych klubów angielskich. Jego strona internetowa wskazuje, iż stanowi bardzo poważne przedsięwzięcie - zarówno sportowe, jak i organizacyjno-finansowe. Siedziba klubu mieści się w Dallas w Teksasie. Działa w nim ponad 70(!) zespołów piłkarskich - o zróżnicowanym charakterze, $\mathrm{w}$ tym wiele dla dziewcząt. Zespoły te uczestniczą na różnych szczeblach i poziomach $\mathrm{w}$ rozgrywkach stanowych oraz regionalnych, a także ogólnokrajowych zdobywając niekiedy - jak się to ujmuje - różnego typu "mistrzostwa”. Teksty zamieszczone na stronach internetowych "Solar Chelsea" zdają się wskazywać, że jest to wręcz klub profesjonalny, co ma bez wątpienia zwiększyć poczucie własnej wartości młodych piłkarzy i piłkarek oraz spotęgować efektywność tego biznesu, jakim jest prowadzenie klubu. W kontekście przygotowania młodzieży napisano, iż celem treningów jest „wyposażenie [piłkarzy] w solidną technikę piłkarską, która będzie wkomponowywała się $w$ realizację założeń taktycznych". Istotne są tutaj umiejętności przyjmowania, kontrolowania i podawania piłki, wpisywania się $\mathrm{W}$ przyjętą taktykę podczas jej posiadania, dryblowania oraz obrony przed atakami przeciwnika, jak również przemieszczania się z nią w kierunku "wolnych przestrzeni" na boisku. Istotne jest także wdrażanie w "działania na rzecz realizacji wspólnego celu", przy zachowaniu równowagi między grą pojedynczego piłkarza a zespołem. Każdy piłkarz „ma wykorzystywać [na boisku szanse] i być kreatywnym". Taktyka na boisku oparta jest na systemie 4-4-2 z jego „wariantami, takimi jak 4-1-4-1 lub 4-2-3-1”. W zależności od grupy wiekowej, treningi i mecze wewnątrz klubu rozgrywane są na mniejszym lub większym boisku, a liczba graczy także jest różnicowana (zajęcia prowadzone są już dla pięciolatków). Pozwala to na optymalne „rozwijanie inteligencji piłkarskiej”. Trenerzy „Solar Chelsea” mają - jak wynika to $\mathrm{z}$ ich zamieszczonych na stronie biografii - zarówno bardzo dobre przygotowanie "formalne" (ukończone kursy i akademie, certyfikaty), jak i bogate doświadczenie trenerskie, a także piłkarskie. W roku 2016 jeden z zespołów tego klubu (U-15) przebywał na obozie treningowym w Hiszpanii, gdzie odbył treningi pod okiem trenerów Realu Madryt i Realu Sociedad. Jego członkowie zasiedli również na trybunach podczas meczu mistrzostw Europy we Francji i w Tuluzie oglądali mecz Włochy-Szwecja ${ }^{35}$.

Zgodzić się więc należy z Gary Hopkinsem, który nazywa amerykańską „młodzieżową piłkę nożną samo-utrzymującą się ekonomiczną maszyną"36.

35 Dane na temat klubu i jego działalności uzyskano z jego strony internetowej: http://www.solarsoccerclub.com/

${ }^{36}$ G. Hopkins, Star-Spangled Soccer, s. 220. 
Roczne opłaty za uczestnictwo w zajęciach w klubie wahają się od 2000 do 10000 dolarów, włączając $\mathrm{w}$ to niekiedy 1500 dolarów za samą rejestrację, 250 dolarów za sprzęt, 250 dolarów za uczestnictwo w meczach i kolejne kwoty na wyjazdy za granicę i udział w obozach ${ }^{37}$ (zespoły młodzieżowe jak to już pokazano powyżej - odwiedzają najlepsze kluby na świecie, takie jak Boca Junior, Manchester United, Real Madryt ${ }^{38}$ ).

Sytuacja amerykańskiej piłki nożnej pozostaje w sprzeczności z ową zasadniczą demograficzną tendencją $w$ tej dyscyplinie, jaką są jej związki $\mathrm{z}$ grupami usytuowanymi raczej nisko $\mathrm{w}$ hierarchii społecznej. Na całym świecie piłka nożna jest preferowana przede wszystkim przez tych właśnie ludzi, podczas gdy w Stanach Zjednoczonych jej uprawianie przynależy w większym stopniu do elity kulturowej.

Jednakże, w kraju tym występuje jeszcze jeden nadzwyczajny paradoks: w piłkę nożną grają tam dzieci bogatych elit i dzieci biednych imigrantów. David L. Andrews, Robert Pitter, Detlev Zwick i Darren Ambrose piszą, że piłka nożna była długo definiowana w Stanach Zjednoczonych jako sport "miejskich imigrantów”; utożsamiano ją z "nie-amerykańską" częścią tożsamości, czy to włoskiej, czy angielskiej, polskiej, hiszpańskiej, meksykańskiej, niemieckiej39. Andrei S. Markovits i Steven L. Hellerman dodają: „W Europie piłka nożna utrzymuje zdecydowanie popularny i masowy (...) wizerunek", podczas gdy w Stanach Zjednoczonych interesują się nią przedstawiciele klasy średniej i miejskich yuppies ${ }^{40}$. Z kolei, David. L. Andrews pisze o tym w sposób następujący:

o ile w wielu ubogich miejskich Hiszpano-Amerykańskich społecznościach piłka nożna jest postrzegana jako symbol nadziei, dumy i tożsamości, to w ramach europejsko-amerykańskich przestrzeni podmiejskiego dobrobytu, dyscyplina ta została w sposób zdecydowany zaadaptowana do codziennego, związanego z praktykowaniem przywilejów, stylu życia41.

Imigranci entuzjastycznie popierają przy tym drużyny piłkarskie - narodowe i klubowe - z krajów swojego pochodzenia, co jest możliwe dzięki globalnej telekomunikacjit2. Natomiast populacja elit nie interesuje się w żadnym stopniu "globalnymi rozgrywkami".

37 Tamże, s. 220.

38 Tamże, s. 225.

${ }^{39}$ D.L. Andrews i in., Soccer, Race, and Suburban Space, s. 198.

40 A.S. Markovits, S.L. Hellerman, Offside: Soccer and American Exceptionalism, s. 30.

${ }^{41}$ D.L. Andrews, Contextualizing Suburban, s. 38.

${ }^{42}$ M. Hase, Race in Soccer, s. 313. 
W ostatecznej konkluzji należy stwierdzić, że społeczeństwo amerykańskie stanowi miejsce szeregu paradoksów - a jeden z nich dotyczy właśnie piłki nożnej. Nie jest ona - jak to wykazałem w poprzednim artykule na ten temat - akceptowana na poziomie narodowym, jednakże służy jako jeden z mechanizmów stratyfikacji społecznej i reprodukcji kulturowej wyższych klas społecznych. Jest to - do pewnego stopnia zdumiewający - przykład kulturowej adaptacji przez klasę dominującą praktyki kulturowej, zdominowanej $w$ innych krajach przez klasy robotnicze, do potwierdzania swojej dominacji.

\section{BIBLIOGRAFIA}

Andrews D.L., Contextualizing Suburban Soccer: Consumer Culture, Lifestyle Differentiation and Suburban America, [w:] Football Culture: Local Contests, Global Visions, red. G.P.T. Finn, R. Giulianotti, London 2000.

Andrews D.L., Pitter R., Zwick D., Ambrose D., Soccer, Race, and Suburban Space, [w:] Sporting Dystopias: The Making and Meaning of Urban Sport Cultures, red. R.C. Wilcox, D.L. Andrews, R. Pitter, R.L. Irvin, Albany 2003.

Foer F., How Football Explains the World, London 2004.

Friedman H.L., Playing to Win. Raising Children in a Competitive Culture, Berkeley 2013.

Gems G.R., Pfister G., Understanding American Sports, Abingdon 2009.

Gromkowska-Melosik A., Elitarne szkolnictwo średnie. Między reprodukcją społecznokulturowa a ruchliwością konkurencyjna, Poznań 2015.

Hase M., Race in Soccer as a Global Sport, [w:] Sports Matters. Race, Recreation and Culture, red. J. Bloom, M.N. Willard, New York 2002.

Hopkins G., Star-Spangled Soccer. The Selling, Marketing and Management of Soccer in the USA, New York 2010.

http:/ / english.stackexchange.com/questions/180899/soccer-mom-why-soccer

http://www.solarsoccerclub.com/

https:/ / soccermommanual.com/where-does-all-the-money-go-youth-soccer-fees /

Markovits A.S., Hellerman S.L., Offside: Soccer and American Exceptionalism, Princeton 2001.

Markovits A.S., Rensmann L., Gaming the World. How Sports are Reshaping Global Politics and Culture, Woodstock 2010.

Melosik Z., Kryzys męskości w kulturze wspótczesnej, Kraków 2006.

Phillipis Academy Andover, Girls Varsity Soccer, 2015 New England Champions; adres internetowy http://www.andover.edu/Athletics/Teams/GSOV/Pages/default.aspx

Slatton M., Where does all the money go? (Youth Soccer Fees), 2.12.2012; portal internetowy: "Soccer Mom. The Manual. Explanations, clarifications and opinions on Youth Soccer in America"

Soccer vs. Football: Field Size; adres interntowy: http://themediadude.blogspot.de/2006/ 06/soccer-vs-football-field-size.html 
Swanson L., Complicating the "Soccer Mom": The Cultural Politics of Forming Class-Based Identity, Distinction and Necessity, Research Quarterly for Excercise and Sport, 2009, $80,2$.

US Youth Soccer, baza danych dotyczących młodzieżowej piłki nożnej w Stanach Zjednoczonych; adres internetowy: http://www.usyouthsoccer.org/media_kit/ataglance/ 